\title{
Immunomodulatory Activities of Selected Essential Oils
}

\author{
Georg Sandner ${ }^{1}\left(\mathbb{D}\right.$, Mara Heckmann ${ }^{1,2}$ and Julian Weghuber ${ }^{1,2, *(D)}$ \\ 1 Center of Excellence Food Technology and Nutrition, University of Applied Sciences Upper Austria, \\ Stelzhamerstraße 23, 4600 Wels, Austria; georg.sandner@fh-wels.at (G.S.); \\ Mara.Heckmann@students.fh-wels.at (M.H.) \\ 2 FFoQSI GmbH-Austrian Competence Centre for Feed and Food Quality, Safety and Innovation, \\ Technopark 1C, 3430 Tulln, Austria \\ * Correspondence: julian.weghuber@fh-wels.at
}

Received: 27 June 2020; Accepted: 31 July 2020; Published: 3 August 2020

\begin{abstract}
Recently, the application of herbal medicine for the prevention and treatment of diseases has gained increasing attention. Essential oils (EOs) are generally known to exert various pharmacological effects, such as antiallergic, anticancer, anti-inflammatory, and immunomodulatory effects. Current literature involving in vitro and in vivo studies indicates the potential of various herbal essential oils as suitable immunomodulators for the alternative treatment of infectious or immune diseases. This review highlights the cellular effects induced by EOs, as well as the molecular impacts of EOs on cytokines, immunoglobulins, or regulatory pathways. The results reviewed in this article revealed a significant reduction in relevant proinflammatory cytokines, as well as induction of anti-inflammatory markers. Remarkably, very little clinical study data involving the immunomodulatory effects of EOs are available. Furthermore, several studies led to contradictory results, emphasizing the need for a multiapproach system to better characterize EOs. While immunomodulatory effects were reported, the toxic potential of EOs must be clearly considered in order to secure future applications.
\end{abstract}

Keywords: essential oils; immunomodulatory; eucalyptus; clove; tea tree; lavender

\section{Introduction-The Immune System and Herbal Medicine}

Recently, there has been growing interest in investigating the immunomodulatory activities of essential oils (EOs) and their individual components. EOs are highly concentrated natural oils derived from plants that consist of aromatic, volatile, secondary plant metabolites. EOs are mostly extracted by steam distillation and exhibit a very intense odor. The main compounds in EOs represent monoand sesquiterpenes and several oxygenated derivatives. Other substances found in the oils include alcohols, aliphatic aldehydes, and esters. Usually, EOs comprise two or three main constituents that determine their biological activities and chemical properties [1,2]. For example, clove essential oil consists of 70-76\% eugenol, a phenolic compound responsible for its antimicrobial and antioxidant activities [3,4]. However, the bioactivity of EOs is influenced by the full composition of the oil, including minor components and possible synergistic, additive, as well as antagonistic effects [5]. Different bioactivity profiles within the same $\mathrm{EO}$ as a result of variations in the chemical composition of the oil have been reported [6]. Factors, such as the environmental conditions (temperature, light, location), physiology of the plant (plant age and plant parts), and genetic aspects, highly influence the chemical composition and thus biological activity of these oils [7]. Novel chemometric approaches could predict the bioactivity of multicomponent substances more reliably $[8,9]$. The applications of EOs are immensely diverse and highly dependent on the plant source. EOs are widely used in aromatherapy, 
cosmetics, the food industry (flavoring and preservative agents), and the pharmaceutical industry (antimicrobial and analgesic agents). The interest in further applications of EOs is steadily increasing. Their immunomodulatory activities are mediated through multiple mechanisms: EOs have been found to stimulate the immune system by increasing the amount of circulating lymphocytes and enhancing their phagocytic activity, thus improving bacterial clearance $[10,11]$. EOs have also been shown to suppress responses involved in inflammation and decrease cytokine production by interfering with key mediators of inflammatory pathways [1-3].

The mammalian immune system is functionally divided into two main compartments: the innate and adaptive immune systems. The innate immune system initiates primary defense reactions and facilitates the elimination or containment of infectious agents by inducing an inflammatory response. Effector cells of the innate immune system include natural killer cells, mast cells, basophils, phagocytic macrophages, monocytes, dendritic cells, neutrophils, and eosinophils. These cells are involved in phagocytosis, cytokine production, antigen presentation, and the release of inflammatory mediators. Invading pathogens are detected via pattern recognition receptors that bind to characteristic foreign structures, such as unmethylated DNA or the bacterial cell wall component, lipopolysaccharide (LPS). This binding activates the cells, triggering phagocytosis of the pathogen and inducing inflammatory mechanisms, including the activation and recruitment of additional effector cells to the site of infection through the secretion of cytokines and chemokines (Figure 1) [4].

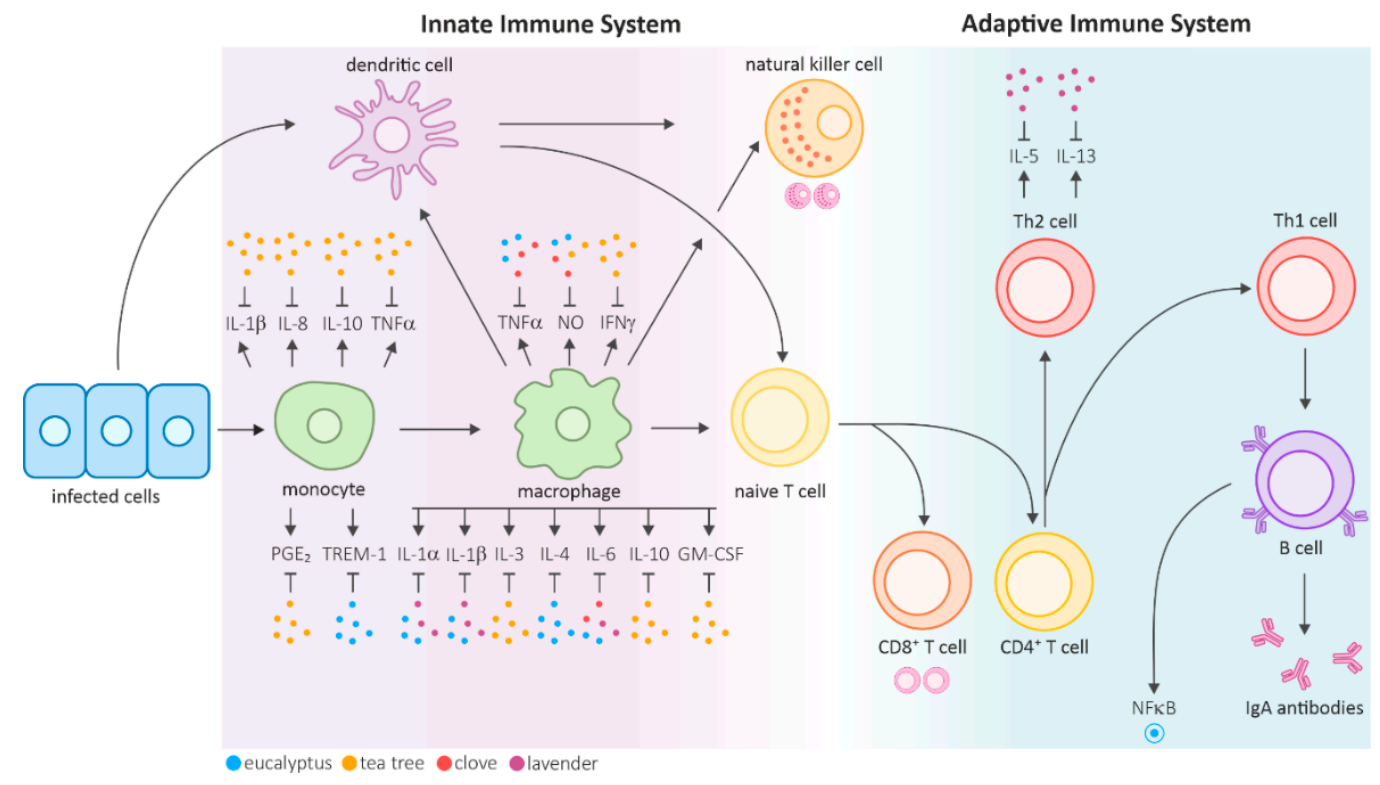

Figure 1. Overview of the mammalian innate and adaptive immune systems and the regulatory effects of selected essential oils on various cytokines shown as dots (adapted from [11]). Antigen-presenting cells (APCs), such as dendritic cells or macrophages, are recruited to the infection site. The released cytokines further activate natural killer cells and lead to the maturation of $\mathrm{T}$ cells. The reviewed studies identified multiple cytokines that were downregulated by eucalyptus, tea tree, clove, and lavender EOs. Specific interleukins and other factors are also expressed in other cell types. Most reviewed research articles focused on monocytes and activated macrophages. Hence, only those effects are highlighted in the figure.

The activation of these nonspecific innate effector mechanisms is critical for the stimulation of the adaptive immune response, a delayed but highly specific defense against the respective infectious agent [10]. The adaptive immune system is characterized by the clonal selection of lymphocytes that respond to a specific antigen and mainly involves antibody-producing B cells and T cells, particularly $\mathrm{CD}^{+} \mathrm{T}$ helper cells and $\mathrm{CD}^{+}$cytotoxic T cells. Naïve CD4 ${ }^{+} \mathrm{T}$ helper (Th) cells differentiate into different subtypes depending on the influencing cytokines. Th1 cells induce inflammatory responses 
and support the immune system in fighting intracellular pathogens, whereas Th2 cells primarily aid the differentiation of $\mathrm{B}$ cells into antibody-producing plasma cells. While extracellular pathogens are contained through humoral, antibody-mediated immune responses, intracellular pathogens are eliminated in the course of cell-mediated immunity, which is a delayed response mainly involving $\mathrm{T}$ cells, macrophages and natural killer cells.

However, since activation of the immune response is linked to tissue damage or destruction, inflammatory reactions are regulated by numerous mechanisms and are usually immediately terminated once the cause of the inflammation has been eliminated [12]. A loss of regulation of inflammatory responses may lead to the development of chronic inflammatory diseases, such as asthma, atherosclerosis, and inflammatory bowel disease [13]. Furthermore, immunodeficiencies can occur when certain components of the innate and adaptive immune system fail due to inherited genetic defects or damage from external factors, such as medication or nutrition [4].

Immunomodulation refers to any processes that alter the immune system either by enhancing (immunostimulation) or suppressing its function. While immunostimulation occurs through the activation of inactive components of the immune system or the augmentation of their activity, immunosuppression describes a reduction of the efficacy of immune responses. This reduction can be beneficial when it assists in diminishing inflammatory and autoimmune responses [14].

Herbal medicine and its applications have gained increasing attention regarding the prevention and treatment of diseases in recent years. Several plants and their extracts have been successfully found to affect $T$ cells and cytokine and antibody production at the cellular and molecular levels [15]. For example, cinnamon bark oil and clove bud oil were shown to increase villi height in the duodenum, jejunum, and ileum of broilers. Antibody titers against Newcastle disease virus were also increased compared to those of control groups. Thus, EOs have been identified as alternatives to antibiotic growth promotors in broilers. Tea tree oil was applied to weaned piglets and improved intestinal mucosal immunity by increasing the interleukin levels IL-2 and IL-10, as well as interferon- $\gamma$ (IFN $\gamma$ ), in the jejunum and ileum. Additionally, the villus length was improved by this treatment. The data revealed that tea tree oil was more effective than standard antibiotics. Tea tree oil was shown to reduce diarrhea and improve growth performance in piglets [16]. Also, ginseng extracts and their EOs were shown to induce immunostimulatory effects, for example by increasing tumor necrosis factor (TNF $\alpha$ ) and IFN $\gamma$ levels or enhancing phagocytic activity [17-19].

Therefore, the promising immunomodulatory effects of plant essential oils could be utilized for alternative treatments. Additionally, natural compounds often show better patient compliance with fewer side effects than standard pharmaceutical drugs. This review focuses on the immunomodulatory responses of four common essential oils (eucalyptus, clove, tea tree, and lavender) that showed the most promising effects according to literature.

\section{Methods}

Literature research was conducted using PubMed, ScienceDirect, and Google Scholar databases and the main searching terms "essential oils", "immunomodulation", "immunostimulation", "immunosuppression", and "inflammation". Prominent essential oils affecting the immune response (mainly documented in eucalyptus, clove, tea tree, and lavender) were then added to the search history resulting in specific publications after the initial literature research. In this review, we focused on recent articles and reviews (2015-2020). Articles presenting interesting findings regarding the four selected essential oils and immune response were chosen for this review. A list of abbreviations is shown in the Appendix A. Results are presented and discussed in the following sections.

\section{Eucalyptus Essential Oil}

The genus Eucalyptus belongs to the Myrtaceae family and comprises approximately 800 species of flowering trees and shrubs that are native to Australia but have been cultivated around the globe [20]. Eucalyptus contains large amounts of volatile compounds (e.g., 1,8-cineole, $\alpha$-pinene, citronellal and 
linalool; a summary of the main components is shown in Figure 2 and Table 1), which are mostly found in the leaves of the plant [21]. Eucalyptus essential oil (EEO) has a long history of medicinal use in the treatment of cough, cold, influenza, and other respiratory infections. The main component is 1,8-cineole (eucalyptol), a monoterpene responsible for its pungent, sharp scent and its therapeutic significance [20]. The compound 1,8-cineole has been shown to exhibit anti-inflammatory and analgesic properties [22] and is used in many oral health care products, such as mouthwashes and chewing gums [20]. Moreover, limonene and $\alpha$-terpineol are common components in EEO. However, the concentrations of these individual compounds vary widely between species [23]. The oil composition also depends on the plant growing conditions, harvest time, extraction time, and temperature [21]. The consumption of EEO at low dosages is generally suggested to be safe for adults, however, if ingested at higher concentrations, EEO can cause systemic toxicity, especially in children. The common side effects of EEO poisoning in children encompass depression of consciousness, vomiting, and seizures. Severe poisoning in children has been reported after ingestion of 3 to $5 \mathrm{~mL}$ of pure EEO [24-26].
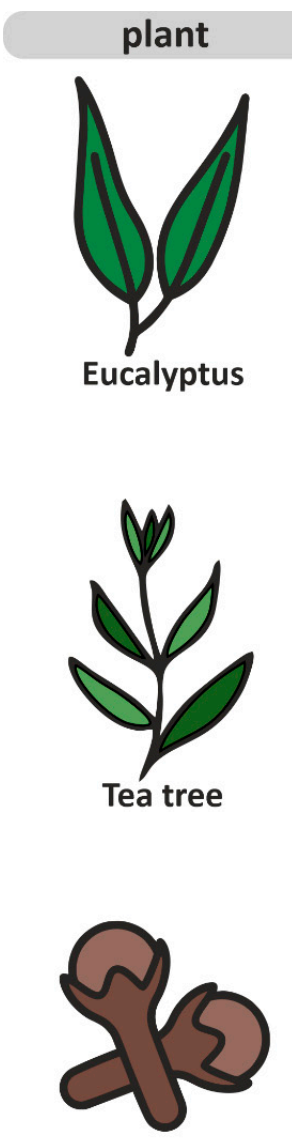

Clove<smiles>C=CCc1ccc(O)c(OC)c1</smiles>

eugenol

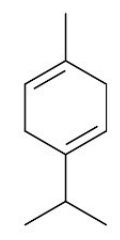

$\gamma$-terpinene<smiles>C=C1CC/C=C(/C)CCC2C(CC2(C)C)C1(C)C</smiles>

$\beta$-caryophyllene<smiles>CC(=O)OC(C)(C)C1CC=C(C)CC1</smiles>

$\alpha$-terpinyl acetate

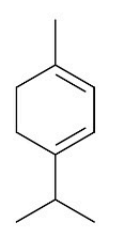

$\alpha$-terpinene
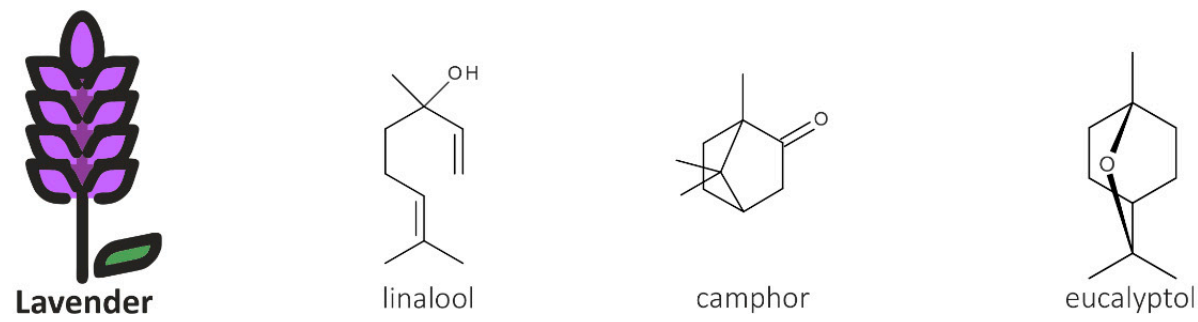

Figure 2. Chemical structures of the main components of the four selected EOs. 
Table 1. Main components of selected essential oils.

\begin{tabular}{cccccccc}
\hline \multicolumn{2}{c}{ Eucalyptus [23,27] } & \multicolumn{2}{c}{ Clove [28,29] } & \multicolumn{2}{c}{ Tea Tree [30,31] } & \multicolumn{2}{c}{ Lavender [32,33] } \\
\hline Compound & Content & Compound & Content & Compound & Content & Compound & Content \\
eucalyptol & $50-80 \%$ & eugenol & $70-76 \%$ & terpinen-4-ol & $30-48 \%$ & linalool & $28-45 \%$ \\
$\alpha$-pinene & $2-26 \%$ & $\beta$-caryophyllene & $10-17 \%$ & $\gamma$-terpinene & $10-28 \%$ & camphor & $3-12 \%$ \\
$\alpha$-terpinyl & $2-5 \%$ & $\alpha$-humulene & $2 \%$ & $\alpha$-terpinene & $5-13 \%$ & eucalyptol & $2-10 \%$ \\
acetate & $2-3 \%$ & eugenyl acetate & $1-12 \%$ & $\alpha$-terpineol & $1-8 \%$ & terpinen-4-ol & $2-7 \%$ \\
$\alpha$-terpineol & $2-3 \%$ & $\alpha$-cubebene & $1-2 \%$ & $p$-cymene & $1-8 \%$ & $\beta$-caryophyllene & $1-6 \%$ \\
trans-pinocarveol & $1-8 \%$ & $\alpha$-copaene & $1-2 \%$ & $\alpha$-pinene & $1-6 \%$ & borneol & $1-10 \%$ \\
globulol & $1-6 \%$ & nerolidol & $0-1 \%$ & limonene & $1-3 \%$ & limonene & $0-3 \%$ \\
limonene & $1-4 \%$ & $<1 \%$ & sabinene & $0-4 \%$ & $\alpha$-pinene & $0-2 \%$ \\
pinocarvone & $1-4 \%$ & farnesol & $<-3 \%$ & $\beta-$-pinene & $0-2 \%$ \\
$\gamma$-terpinene & $1-2 \%$ & methyl chavicol & $<1 \%$ & $\delta$-cadinene & $0-3 \%$ & myrcene & $0-2 \%$ \\
$p$-cymene & $1-7 \%$ & caryophyllene & $<1 \%$ & eucalyptol & $0-15 \%$ & & \\
& & oxide & & & & &
\end{tabular}

Recently, the immunomodulatory effects of EEO and its constituents have gained increased attention. Serafino et al. [34] investigated the impact of EEO on human monocyte-derived macrophages (MDMs) in vitro by confocal microscopy after the administration of fluorescent beads. The results showed drastically increased phagocytic activity in human MDMs during EEO treatment compared to those that were treated with LPS. In the untreated control groups, $13.7 \%$ of cells showed phagocytic activity with a mean of 11 phagocytosed beads per cell. LPS treatment for $6 \mathrm{~h}$ slightly increased the percentage of phagocytic cells to $18.26 \%$ and did not affect the number of phagocytosed beads, whereas treatment with $0.008 \%$ EEO increased the percentage to $27.1 \%$ with a mean of 24 phagocytosed beads per cell after $24 \mathrm{~h}$ of treatment. Additionally, pretreatment with EEO for $24 \mathrm{~h}$ before LPS challenge increased the phagocytic activity of human MDMs compared to that of LPS treatment alone. Active cell motility might contribute to the enhanced phagocytic ability, as MDMs treated with EEO demonstrated elongated lamellipodia and filopodia. A nonspecific effect of EEO on the phagocytic activity of MDMs was excluded by testing other oil preparations, which did not affect MDM phagocytic activity. Despite this stimulation, the LPS-induced production of proinflammatory cytokines was significantly reduced in cells that were pretreated with EEO. This effect was especially evident for the cytokines IL-4, IL-6, and TNF $\alpha$. When nocodazole was added, the phagocytic activity of EEO-pretreated cells was inhibited, while the activity of LPS-stimulated cells was not influenced, suggesting that the EEO-mediated enhancement of phagocytosis was dependent on the microtubule network and was mediated through different mechanisms than LPS-induced phagocytosis, possibly involving different phagocytic receptors.

Furthermore, the study by Serafino et al. [34] revealed the impact of EEO on the phagocytic abilities of peripheral blood monocytes and granulocytes in immunocompetent and immunosuppressed rats after in vivo administration. In immunocompetent rats, EEO treatment significantly increased the percentage of circulating monocytes and simultaneously increased phagocytic activity and the expression of the CD44 receptor, which mediates adhesion to the endothelium, thus promoting extravasation [35]. In 5-fluorouracil-induced immunosuppressed rats, the administration of EEO led to a recovery of the percentage of circulating granulocytes and restored the phagocytic abilities of granulocytes and monocytes. Since 5-fluorouracil is commonly used in chemotherapy, these results also suggest a possible role of EEO in novel combination therapies to improve the treatment of cancer [34].

Yadav and Chandra [36] examined the effect of EEO and its main constituent 1,8-cineole on the phagocytic activity of lung alveolar macrophages. When cells were pretreated with $0.02 \%$ EEO $3 \mathrm{~h}$ before bacterial infection, an increase in the phagocytic activity of alveolar macrophages and intracellular pathogen clearance was observed. These results are consistent with those of Serafino et al. [34]. Additionally, pretreatment with EEO reduced the production of LPS-induced proinflammatory mediators, such as TNF $\alpha, \mathrm{IL}-1 \beta, \mathrm{IL}-1 \alpha$, and NO in lung alveolar macrophages. Furthermore, 1,8-cineole demonstrated a similar anti-inflammatory effect but only affected intracellular IL- $1 \alpha$, IL-1 $\beta$, and IL- 6 . However, 1,8-cineole seems to exert a strong inhibitory effect on TNF $\alpha$ 
production in monocytes. In a previous study [37], 1,8-cineole pretreatment was shown to reduce TNF $\alpha$ and IL-1 $\beta$ production in human monocytes by $99 \%$ and $84 \%$, respectively. Reduced IL- $1 \beta$ levels might result from the reduced expression of the nod-like receptor NLRP3 [36]. Unlike toll-like receptors, nod-like receptors are activated inside the cell and are part of the inflammasome, a multiprotein innate immune complex that is responsible for inflammatory responses. Active inflammasomes can lead to caspase 1-mediated activation of IL-1 $\beta$ [38]. This effect suggests a potential therapeutic impact of EEO on inflammatory diseases involving the inflammasome, such as type 2 diabetes [39], inflammatory bowel disease [40], and atherosclerosis [41].

In the study by Yadav and Chandra [36], EEO pretreatment also reduced mRNA expression of triggering receptor expressed on myeloid cells (TREM-1) [34]. TREM-1 induces the release of cytokines, such as IL-1 $\beta$ and TNF $\alpha$, amplifying the inflammatory response [42]. Additionally, a reduction in LPS-induced phosphorylation of p38-mitogen-activated protein kinase (p38 MAPK) and nuclear factor kappa-light-chain-enhancer of activated B-cells (NFkB) was observed following EEO pretreatment [34]. P38 MAPK is associated with various chronic inflammatory diseases, such as rheumatoid arthritis and inflammatory bowel disease. Selective inhibition of p38 MAPK could lead to an important approach in the anti-inflammatory treatment of chronic diseases [43]. The decreased phosphorylation of $N_{k} B$ and p38 MAPK and the mRNA expression of TREM-1 also correlate with the reduction in the levels of TNF $\alpha$, IL-1 $\beta$, IL-6, and NO. Moreover, 1,8-cineole increased the phosphorylation of NFkB in lung alveolar macrophages, suggesting that different constituents of EEO might be responsible for the reduction in $\mathrm{NF}_{\kappa} \mathrm{B}$ activity [36]. In human monocytes, pretreatment with $\alpha$-pinene was shown to inhibit the activity of NFKB [44], whereas 1,8-cineole demonstrated no effect on NFKB [45]. These results indicate that EEO exhibits different cell-type-specific effects on LPS-mediated inflammatory responses.

Hotta et al. [1] analyzed the impact of EOs on cyclooxygenase (COX-2) expression using bovine arterial endothelial cells and demonstrated that 0.01\% EEO suppressed LPS-induced COX-2 promoter activity by $25 \%$. Thyme and clove essential oils exhibited even stronger effects than those of EEO. While COX-1 is constitutively expressed in many cells and tissues, COX-2 is usually absent but is induced through numerous intra- and extracellular stimuli, including LPS and proinflammatory cytokines. Thus, COX-2 is a key mediator of inflammatory pathways [46]. Thyme and clove oils act as peroxisome proliferator-activated receptor (PPAR) agonists, thereby initiating a negative feedback loop that regulates COX-2 expression. EEO induced PPAR activation, but the effect was not significant. It is questionable whether single compounds in EEO exhibit stronger PPAR agonist effects than EEO itself to inhibit increased COX-2 expression. Further research is required to obtain a comprehensive outlook on this matter.

\section{Clove Essential Oil}

Along with Eucalyptus, clove (Syzygium aromaticum) belongs to the Myrtaceae family. Clove is an evergreen tree that is native to Indonesia and is mostly grown for its aromatic flowers. Clove essential oil (CEO) has been used in traditional medicine mainly as a pain reliever in dental care and in the treatment of burns and wounds. The main component in CEO is eugenol (Figure 2 and Table 1), a phenolic compound that contributes to the oil's warm, spicy scent and exhibits many pharmacological properties [47]. The antioxidant, anti-inflammatory [48], antimicrobial [49], and analgesic [50] effects of eugenol have been previously documented. The oil is also composed of numerous other compounds, including eugenol acetate, $\beta$-caryophyllene, and $\alpha$-humulene [51]. Generally, data on the cytotoxicity of EOs and their active cytotoxic components are limited. CEO has been shown to be highly toxic to human fibroblasts and endothelial cells at a concentration of $0.03 \%$. This effect is mostly attributable to eugenol, however the cytotoxicity profile of CEO may be characterized by more than one constituent [52]. Additionally, CEO exhibits significant hepatotoxic effects. Ingestion of $10 \mathrm{~mL} \mathrm{CEO} \mathrm{can} \mathrm{cause} \mathrm{hepatoxicity} \mathrm{and} \mathrm{renal} \mathrm{dysfunction} \mathrm{[53].}$

Many studies investigating the impact of CEO and its constituents on immune responses have resulted in conflicting findings. Carrasco et al. [54] examined the effect of CEO containing $>98 \%$ 
eugenol on humoral and cell-mediated immune responses in mice in vivo. Daily oral administration of CEO $(100,200$, and $400 \mathrm{mg} / \mathrm{kg}$ ) for 7 days significantly increased the total white blood cell count in immunocompetent mice after immunization with sheep red blood cells (SRBCs) on day 0 , and this effect was shown to be dose-dependent. In immunocompetent mice, CEO might stimulate immune responses by activating the hematopoietic system and increasing the number of circulating lymphocytes. Additionally, following cyclophosphamide-induced immunosuppression in mice, CEO $(400 \mathrm{mg} / \mathrm{kg}$ ) restored the total white blood cell count to the initial values after 7 days. While humoral immune responses were not significantly affected by CEO in immunocompetent mice, the production of circulating anti-SRBC antibodies drastically increased in cyclophosphamide-suppressed mice. A delayed-type hypersensitivity (DTH) assay was performed to identify the influence of CEO on cell-mediated immunity. After $24 \mathrm{~h}$ of antigen challenge, CEO-treated immunocompetent mice demonstrated a significant increase in foot-paw volume. CEO was effective in stimulating cell-mediated immunity in immunocompetent mice and in restoring the white blood cell counts and humoral immunity in immunosuppressed mice.

Conversely, in a similar study conducted by Halder et al. [55], $0.1 \mathrm{~mL} / \mathrm{kg} \mathrm{CEO,} \mathrm{which} \mathrm{consisted}$ of $87.34 \%$ eugenol, was administered daily for two weeks and led to a significant decrease in paw volume in rats. The authors suggest that CEO may indirectly reduce inflammation by inhibiting cell-mediated immune responses. Additionally, improvements in humoral primary and secondary immune responses were documented, which positively affected lymphocyte functions.

Islamuddin et al. [56] analyzed the immunomodulatory effect and therapeutic efficacy of eugenol emulsion (EE) in experimental visceral leishmaniasis (VL). After 10 days of EE treatment, enhanced cell-mediated immune responses, as identified by a significant augmentation in paw thickness and humoral immune responses in mice, were observed in vivo. EE treatment also led to an increase in IFN $\gamma$-secreting $\mathrm{CD}^{+}$and $\mathrm{CD}^{+}$splenic $\mathrm{T}$ cells, along with $\mathrm{CD}^{+}$central memory $\mathrm{T}$ lymphocytes. The generation of central memory cells was consistent with the upregulated expression of CD44 and CD62L, two adhesion molecules that are highly expressed on central memory $\mathrm{T}$ cells [56]. In peritoneal macrophages, EE significantly enhanced the expression of CD80 and CD86 [56]. These costimulatory molecules play pivotal roles in the activation of lymphocytes and the secretion of cytokines and are, therefore, critical to the initiation and maintenance of immune responses [57]. Additionally, the proliferation of antigen-stimulated splenocytes and lymphocytes and NO production were significantly augmented 10 days after EE treatment. EE also showed promising therapeutic potential in the treatment of VL by reducing hepatic and splenic parasitic burdens, as indicated by decreased spleen and liver weights. Furthermore, alterations in cytokine levels upon EE treatment were identified. While the production of the classic Th1 cytokines IFN $\gamma$ and IL-2 increased, serum levels of cytokines released from Th2 cells, particularly IL-4 and IL-10, decreased. This finding provides further evidence for the suitability of EE for VL therapy, since IL-4 and IL-10 are associated with this disease [56].

Dibazar et al. [58] demonstrated both anti- and proinflammatory in vitro effects of CEO on LPS-stimulated mouse peritoneal macrophages. Significant suppression of NO and TNF $\alpha$ production and release were reported after $48 \mathrm{~h}$ of incubation. In previous studies, eugenol was shown to inhibit the expression of inducible nitric oxide synthase (iNOS), as well as the release of TNF $\alpha$, in macrophages and might, therefore, be responsible for this effect $[59,60]$. Additionally, IL-6 production was stimulated in a particular experiment [58]. This effect might occur due to the reduced NO levels, since NO has been associated with the downregulation of LPS-induced IL-6 production in alveolar macrophages [61]. However, these findings are inconsistent with the results from Bachiega et al. [62], who demonstrated that CEO could inhibit the production of the proinflammatory cytokine IL-6 in murine macrophages. These contradictory results highlight the difficulties affiliated with evaluating the effects of CEO and its constituents, especially eugenol, on inflammation and on the overall immune response. As mentioned above, the bioactivity of EOs is influenced by many factors and varies with the chemical composition of the oil. The different geographical origin of the clove flower buds and extraction methods used in these 
two studies might be responsible for the obtained contradictory results. Further research with different doses of CEO and eugenol, as well as other target cell types, may provide a better understanding.

\section{Tea Tree Essential Oil}

Melaleuca alternifolia, commonly known as tea tree, is a member of the botanical family Myrtaceae and endemic to Australia. The essential oil from this tree has long been used in folk medicine as a topical medication to treat bruises and infected injuries. Tea tree essential oil (TTO) is composed of approximately 100 volatile compounds, the majority being terpene hydrocarbons. The main active component has been found to be terpinen-4-ol, a monoterpene with strong antimicrobial properties (Figure 2 and Table 1) [63]. TTO is toxic when ingested in higher concentrations and can cause skin irritation and allergic reactions in predisposed individuals. Due to their low body weight, children are more vulnerable to TTO poisoning. Ingestion of less than $10 \mathrm{~mL}$ pure TTO can cause central nervous system depression and ataxia in children. However, data on the toxicity profile of TTO are limited and the responsible components have not been identified [64].

Hart et al. [2] investigated the effect of TTO on the production of inflammatory mediators by LPS-activated human peripheral blood monocytes in vitro. The results indicated that some constituents of TTO appeared to be toxic to monocytes in culture, and the water-soluble components terpinen-4-ol, $\alpha$-terpineol, and 1,8-cineole could suppress the production of inflammatory mediators in a nontoxic manner. Significantly reduced levels of TNF $\alpha, \mathrm{IL}-1 \beta, \mathrm{IL}-8, \mathrm{IL}-10$, and prostaglandin $\mathrm{E}_{2}$ were identified after $40 \mathrm{~h}$ of incubation with the water-soluble components of TTO. In LPS-stimulated human macrophages, TTO demonstrated a similar inhibitory effect on IL-1 $\beta$ and IL-10 production, but TNF $\alpha$ levels remained unaltered [3]. These partially contradictory results suggest that the biological activity of TTO strongly depends on the cell type, as well as the composition and concentration of the oil. Both studies identified terpinen-4-ol as being primarily responsible for these effects, most likely by interfering with the NFKB, p38, or ERK/MAPK pathway.

Recently, the immunomodulatory effect of Melaleuca alternifolia concentrate (MAC) has been investigated. MAC represents a refined product derived from TTO that has very low concentrations of hydrophobic monoterpenes, but its major component is still terpinene-4-ol. Low et al. [65] examined the impact of MAC on protein expression in macrophage-like cell lines. MAC inhibits the phosphorylation of inhibitor of $\kappa B$ kinases $(\mathrm{I} \kappa \mathrm{B})$, a mechanism that is necessary for the activation of $N F \kappa B$ and downstream target genes. Normally, IKB is bound to inactive NFkB, which is activated and released upon IKB phosphorylation [66]. This inhibition of $\mathrm{NF} \kappa \mathrm{B}$ translocation results in decreased levels of certain LPS-induced proinflammatory cytokines, as well as reduced iNOS expression and NO production [65]. Lee et al. [67] verified and extended these observations by demonstrating that MAC not only inhibited the phosphorylation of I $\mathrm{KB}$ but also increased its concentration in the cytosol. Additionally, the study revealed that MAC positively regulated heme oxygenase- 1 (HO-1) expression by inducing the activation and translocation of NF-E2-related factor 2 (Nrf2). Since the Nrf2-HO-1 pathway is greatly involved in anti-inflammatory processes and inhibits the COX-2 and iNOS signaling pathways, these results suggest a promising role of TTO and its extracts in the treatment of inflammatory diseases.

Budhiraja et al. [68] also reported immunostimulatory effects of TTO. The study demonstrated that both TTO and terpinen-4-ol similarly induce the differentiation of immature myelocytes into active phagocytizing monocytes and increase the expression of CD11b, a receptor that is partially responsible for the phagocytosis of opsonized bacteria and fungi by leukocytes. While much research has been undertaken on the immunoinhibitory effects of TTO, little is known about its potential as an immunostimulatory agent.

\section{Lavender Essential Oil}

Lavender essential oil (LEO) is commonly obtained from Lavandula angustifolia, a species of flowering plants belonging to the Lamiaceae family that is widely cultivated in the Mediterranean 
region. This aromatic plant has a long history of use in traditional medicine as a natural remedy for various inflammatory disorders. LEO is steam-distilled from the flowers and leaves of the plant and contains high concentrations of the monoterpenoids linalool, linalyl-acetate, 1,8-cineole, camphor, and terpinen-4-ol (Figure 2 and Table 1). However, the oil composition strongly varies depending on the geographical origin of the plant, environmental factors and extraction parameters [69,70]. LEO is regarded as one of the mildest essential oils, however concerns about possible allergenic or irritant skin reactions are rising. LEO has been shown to be cytotoxic to human endothelial cells and fibroblasts at a concentration of $0.25 \%$. The cytotoxicity is mainly attributable to the oil's major constituent linalool and linalyl acetate [71]. Additionally, linalyl acetate has been previously shown to exhibit genotoxic effects on human lymphocytes [72].

Giovannini et al. [73] demonstrated a protective effect of LEO on human MDMs upon infection with Staphylococcus aureus in vitro, as indicated by a significant increase in phagocytic activity and a reduction in intracellular bacterial replication. The enhancement of bacterial clearance might occur due to the upregulated expression of genes involved in generating reactive oxygen species (CYBB and NCF4). These observations suggest that LEO could stimulate innate immune responses to bacteria. Additionally, LEO exerts regulatory effects on the inflammatory response by inhibiting the production of several bacterial-induced proinflammatory cytokines, including IL- $1 \alpha$, IL-1 $\beta$, and IL-6, by macrophages. Similar to TTO, LEO is thought to exhibit its anti-inflammatory effects by inducing the expression of HO- 1 . The authors of this study could not identify the single constituent of LEO that is responsible for these immunomodulatory effects and instead suggested that the bioactivity may depend on the whole phytocomplex of the oil.

Chen et al. [74] investigated the impact of aromatherapy massage with $2 \%$ LEO on the stress level and immune functions of pregnant women. Twenty-four healthy pregnant women received 10 aromatherapy massages every other week for 20 weeks. Compared to the control group, who only received routine prenatal care, the intervention group demonstrated significantly elevated salivary IgA and reduced cortisol levels immediately after aromatherapy massage. Chen et al. also documented long-term effects on salivary IgA levels, which serve as indicators of immune function. In a similar study, aromatherapy massage with an oil blend of lavender, cypress, and sweet marjoram led to a drastic increase in peripheral blood lymphocytes in healthy subjects, presumably due to the documented increase in $\mathrm{CD}^{+} \mathrm{T}$ cells and $\mathrm{CD}^{+} 6^{+}$cells [75]. These results provide evidence that aromatherapy massage with LEO could significantly stimulate immune functions and diminish stress. Additionally, a significant impact of inhaled LEO was observed in the treatment of migraine headache in a placebo-controlled clinical trial [76]. Therefore, LEO might be an effective alternative for reducing symptoms caused by acute migraine.

Ueno-lio et al. [77] examined the potent anti-inflammatory effect of LEO on experimentally induced bronchial asthma in mice. Asthma is strongly driven by Th2 cells and their cytokines IL-4, IL-5, and IL-13, which induce eosinophilic inflammation in the airway [78]. Inhalation of LEO led to the suppression of allergic airway inflammation, as evidenced by reduced cell accumulation and mucus production. LEO decreased IL-5 and IL-13 production and inhibited eosinophilic infiltration. Additionally, mucus production was controlled through the downregulation of MUC5B, the gene encoding the major gel-forming mucin. The authors suggest that this downregulation might occur through the inhibition of $N F \kappa B$ activation induced by certain components of LEO, since NFkB has been found to stimulate MUC5B expression [79]. These observations reveal that LEO exhibits strong immunomodulatory effects and shows great potential as an alternative anti-inflammatory medicine for bronchial asthma.

\section{Conclusions}

This review highlights the growing interest in the immunomodulatory effects of plant-derived EOs and their main components. Protective attributes, such as antibacterial, antioxidative, or anti-inflammatory properties are already well described. However, the immunomodulatory 
effects of EOs have been considered only in a limited manner. Additionally, plant extracts induce few reported side effects compared to those of immunomodulatory pharmaceutical drugs. The current literature strengthens the potential of various EOs as suitable immunomodulatory alternative treatments for infectious or immune diseases. Furthermore, these compounds also provide good efficacy as preventive medicine, which promotes a general healthy lifestyle.

The results reviewed in this study revealed a significant reduction in relevant cytokines, such as IL-1 $\alpha$, IL-1 $\beta$, IL-3, IL-4, IL-5, IL-6, IL-8, IL-10, IL-13, TNF $\alpha$, NO, and IFN $\gamma$, which were measured mainly in monocytes and activated macrophages. Studies also showed both a reduction of proinflammatory cytokines by M1 activated macrophages, such as IL-1, IL6, NO, or TNF $\alpha$, as well as the production of anti-inflammatory markers, such as IL-5, IL-13, expression of HO-1 (Nrf2-HO-1 pathway), increased production of $\mathrm{CD}^{+}, \mathrm{CD} 16^{+}$cells, and IgA by activation of $\mathrm{M} 2$ macrophages. Additionally, selected EOs were identified to alter the NFkB and p38 MAPK pathways. The balance of these pathways and factors in pro- or anti-inflammatory functions remains critical in immunomodulation. Since macrophages play an important role in defense of microbial infections, tissue repair, and tumors, regulation via EOs might also stimulate results regarding these applications [80]. The main results of the reviewed articles are summarized in Table 2. Furthermore, EEO increased the phagocytic activities of macrophages and peripheral blood monocytes and enhanced bacterial clearance. EEO restored the number of circulating granulocytes and their phagocytic ability in immunosuppressed models. CEO additionally was shown to stimulate cell-mediated immunity in immunocompetent mice and restore total white blood cell count (WBC) and humoral immunity in immunosuppressed mice. Importantly, several studies presented in this review provided contradictory results. Here, multiple parameters, such as location and climatic conditions for cultivation, extraction procedures, applied concentration, general application, as well as the testing organism remain critical factors. The geographical origin, environment, and extraction parameters highly affect the final extract composition. Variations in the main composition, but also changes in minor substances, can lead to great variations, representing a challenging task for commercial exploitation and exploration [81,82]. Chemometric approaches might reliably predict the bioactivity of multicomponent substances in the future for better characterization of EOs and an improved comparability within studies [8,9]. Due to hydrophobic properties and viscosity, the application of EOs to in vitro cell culture remains very challenging, which might also contribute to contradictory results across the reviewed studies. The applied dose and application (oral, inhalation, skin) also influences the EO efficacy. Finally, the selected in vivo organism or in vitro cell type strongly influences EO performance, rendering a precise prediction highly difficult.

The effects of EOs have mainly been examined at the cellular level, including in monocytes, macrophages, and Th cells, in the context of the molecular impacts on cytokines or immunoglobulins. Only a few studies addressed possible genetic regulations and mechanisms [83]. Further research should focus on the genetic regulatory pathways involved. Additionally, most of the analyzed data were derived from in vitro cell culture and in vivo mouse/rat experiments. In fact, there is a huge gap between in vitro studies and in vivo or clinical trials. Besides aromatherapy clinical trials, few data are available describing the immunomodulatory effects of EOs in humans. The U.S. Food and Drug Administration (FDA) considers many EOs as "Generally Recognized As Safe" (GRAS), therefore very little attempt has been made to investigate toxic effects on the body. Nevertheless, multiple studies revealed the toxic effects of EOs, clearly showing the need for appropriate testing systems for identifying their modes of action in the metabolism. Recently, even low concentrations of selected EOs showed toxic potential regarding respiratory disorders, mucous membrane irritation, acute toxicity, and organ toxicity $[84,85]$. This holds true also for the selected essential oils in this review. EEO was shown to cause acute poisoning symptoms, CEO revealed hepatocytic effects, and TTO and LEO exhibit skin irritation and allergic reactions. There is also evidence of cytotoxic effects in selected cell types. Hence, there is a great demand for comprehensive toxicity testing prior to applications in food, feed, and pharmaceutical products. Alternative systems, such as 3D-cell culture, organs-on-chip, 
or in vivo models like Caenorhabditis elegans and Drosophila melanogaster, might lead to novel insights and predictive approaches in this emerging topic.

Table 2. Overview of the immunomodulatory effects and concentrations of selected essential oils.

\begin{tabular}{|c|c|c|}
\hline Essential Oil & Effects on Immune Functions & Concentrations \\
\hline Eucalyptus & $\begin{array}{c}\text { Increased the phagocytic activities of macrophages and peripheral } \\
\text { blood monocytes and enhanced bacterial clearance [34,36]; restored the } \\
\text { number of circulating granulocytes and their phagocytic ability in } \\
\text { immunosuppressed models [34]; inhibited the production of IL- } 1 \alpha \text {, } \\
\text { IL-1 } \beta \text {, IL-4, IL-6, TNF } \alpha \text {, and NO [34,36]; attenuated the activation of } \\
\text { p38 MAPK, NFKB, and TREM-1 [36]; suppressed COX-2 promoter } \\
\text { activity by } 25 \%[1]\end{array}$ & $\begin{array}{c}\text { EEO } 0.008 \text { and } 0.016 \% \text { [v/v] (in vitro), EEO } 12 \\
\mathrm{mg} / \mathrm{kg} / \text { day for } 15 \text { days (in vivo) [34]; EEO and } \\
1,8 \text {-cineole } 0.02 \% \text { [v/v] (in vitro) [36]; EEO } 0.01 \% \\
\text { (in vitro) [1] }\end{array}$ \\
\hline Clove & $\begin{array}{l}\text { Many contradictory results; stimulated cell-mediated immunity in } \\
\text { immunocompetent mice and restored WBC count and humoral } \\
\text { immunity in immunosuppressed mice [54]; inhibited cell-mediated } \\
\text { responses and improved humoral immune responses in } \\
\text { immunocompetent rats [55]; suppressed NO and TNF } \alpha \text { production by } \\
\text { macrophages [58]; stimulated [58] and inhibited [62] IL-6 production; } \\
\text { enhanced cell-mediated and humoral immune responses in } \\
\text { experimental VL [56]; suppressed COX-2 promoter activity by } 40 \% \text { [1] }\end{array}$ & $\begin{array}{l}\text { CEO (<98\% eugenol) } 100,200,400 \mathrm{mg} / \mathrm{kg} / \mathrm{day} \\
\text { for } 7 \text { days (in vivo) [54]; CEO ( } 87.34 \% \text { eugenol) } \\
0.1 \mathrm{~mL} / \mathrm{kg} / \text { day (in vivo) [55]; ethanolic CEO } \\
\text { extract ( } 74 \% \text { eugenol), aqueous CEO extract } \\
(43 \% \text { eugenol) } 0.001-1000 \mu \mathrm{mg} / \mathrm{mL} \text { (in vitro) [ } 58] \text {; } \\
\text { clove extract } 100 \mu \mathrm{g} / \text { well, eugenol extract } 50 \\
\text { and } 100 \mu \mathrm{g} / \text { well (in vitro) [ } 62] \text {; eugenol } \\
\text { emulsion } 25,50 \text {, and } 75 \mathrm{mg} / \mathrm{kg} / \text { day for } 10 \text { days } \\
\text { (in vivo) [56]; CEO } 0.01 \% \text { (in vitro) [1] }\end{array}$ \\
\hline Tea tree & $\begin{array}{l}\text { Stimulated the differentiation of immature myelocytes into active } \\
\text { phagocytizing monocytes and increased CD11b receptor expression } \\
\text { [68]; suppressed the production of TNF } \alpha \text {, IL-1 } \beta, \text { IL-8, IL-10, and } \\
\text { prostaglandin } \mathrm{E}_{2} \text { by blood peripheral monocytes [2]; MAC reduced the } \\
\text { production of NO and proinflammatory cytokines, inhibited NFKB } \\
\text { activation and induced HO-1 expression }[65,67]\end{array}$ & $\begin{array}{l}\text { TTO and terpinen-4-ol } 20-90 \mu \mathrm{mol} / \mathrm{L} \text { (in vitro) } \\
\text { [68]; water soluble components of TTO at } \\
0.125 \% \text { (42\% terpinen-4-ol, } 3 \% \alpha \text {-terpineol and } \\
2 \% 1,8 \text {-cineole) (in vitro) [2]; MAC (60-64\% } \\
\text { terpinen-4-ol, 8-14\% p-cymene) } 0.004-0.016 \% \\
\text { [v/v] (in vitro) [65]; MAC }(60 \% \text { terpinen-4-ol) } \\
\text { 0.01-0.5\% (in vitro) [67] }\end{array}$ \\
\hline Lavender & $\begin{array}{l}\text { Increased the phagocytic activity of macrophages and reduced } \\
\text { intracellular bacterial replication and the production of IL- } 1 \alpha, \text { IL-1 } \beta \text {, } \\
\text { and IL-6 [73]; attenuated IL-5 and IL-13 secretion and inhibited } \\
\text { eosinophilic infiltration and mucus production in mouse asthma } \\
\text { models [77]; aromatherapy massage increased IgA levels [74] and the } \\
\text { number of CD8 } 8^{+} \text {and CD16 cells [75] }\end{array}$ & $\begin{array}{c}\text { LEO ( } 39 \% \text { linalool, } 11.97 \% \text { camphor, } 10.54 \% \\
\text { eucalyptol) dilution of 1:50,000 for } 10^{6} \text { cells } \\
\text { (in vitro) [73]; LEO ( } 31.78 \% \text { linalyl acetate, } \\
25.56 \% \text { linalool) } 20 \mu \mathrm{L} \text { on } 10 \times 10 \text { filter paper } \\
\text { (in vivo) [77]; LEO } \% \text { (aromatherapy clinical } \\
\text { trial) [74]; essential oil blend of lavender } \\
\text { (36.31\% linalool, } 34.05 \% \text { linalyl acetate), cypress } \\
\text { (61.85\% } \beta \text {-pinene, } 15.2 \% \text {-carene), and sweet } \\
\text { marjoram ( } 21.26 \% \text { terpinen-4-ol, } 13.46 \% \\
\gamma \text {-terpinene) (aromatherapy clinical trial) [75] }\end{array}$ \\
\hline
\end{tabular}

Especially for determining effective and critical toxicological values as well as acute toxicity, more research should be conducted in alternative model organisms. This fact represents a key point for future therapeutic applications. In this regards, multifactor approaches will be necessary in order to avoid over- or underestimation of the toxicological properties resulting in unjustified restrictions or safety attestation.

However, EOs have been successfully applied as feed additives to broiler chickens or weaned piglets and have clearly shown immunostimulatory effects, while no biotoxicity was observed. Additionally, more clinical trials focusing on immunomodulation are needed, since in vitro cell culture and in vivo experiments showed strong evidence in the context of the immunomodulatory properties of selected EOs.

Funding: This research received no external funding.

Acknowledgments: This work was created within a research project of the Austrian Competence Centre for Feed and Food Quality, Safety and Innovation (FFoQSI). The COMET-K1 Competence Centre FFoQSI is funded by the Austrian ministries BMVIT, BMDW, and the Austrian provinces Niederoesterreich, Upper Austria and Vienna within the scope of COMET-Competence Centers for Excellent Technologies. The program COMET is handled by the Austrian Research Promotion Agency FFG. This work was also funded by the Christian Doppler Forschungsgesellschaft (Josef Ressel Center for Phytogenic Drug Research). Also, special thanks to Bettina Schwarzinger (University of Applied Sciences Upper Austria, Center of Excellence Food Technology and Nutrition) for kindly preparing the chemical structures for Figure 2.

Conflicts of Interest: The authors declare no conflict of interest. The funders had no role in the design of the study; in the collection, analyses, or interpretation of data; in the writing of the manuscript, or in the decision to publish the results. 


\section{Appendix A}

Table A1. List of Abbreviations.

\begin{tabular}{|c|c|}
\hline Abbreviation & Explanation \\
\hline $\mathrm{APC}$ & antigen-presenting cells \\
\hline CEO & clove essential oil \\
\hline COX-2 & cyclooxygenase \\
\hline DTH & delayed-type hypersensitivity \\
\hline EE & eugenol emulsion \\
\hline EEO & eucalyptus essential oil \\
\hline EO & essential oil \\
\hline $\mathrm{HO}-1$ & heme oxygenase- 1 \\
\hline $\mathrm{IFN} \gamma$ & interferon- $\gamma$ \\
\hline IL & interleukin \\
\hline iNOS & inducible nitric oxide synthase \\
\hline IкB & inhibitor of $\kappa B$ kinase \\
\hline LEO & lavender essential oil \\
\hline LPS & lipopolysaccharide \\
\hline MAC & Melaleuca alternifolia concentrate \\
\hline MDM & monocyte-derived macrophages \\
\hline MUC5B & gel-forming mucin \\
\hline NFKB & nuclear factor kappa-light-chain-enhancer of activated B-cells \\
\hline NLR & nod-like receptor \\
\hline NO & nitric oxide \\
\hline Nrf2 & NF-E2-related factor 2 \\
\hline p38 MAPK & p38-mitogen-activated protein kinase \\
\hline PPAR & peroxisome proliferator-activated receptor \\
\hline SRBC & sheep red blood cells \\
\hline $\mathrm{TNF} \alpha$ & tumor necrosis factor $\alpha$ \\
\hline TREM-1 & triggering receptor expressed on myeloid cells \\
\hline TTO & tea tree oil \\
\hline VL & visceral leishmaniasis \\
\hline WBC & total white blood cell count \\
\hline
\end{tabular}

\section{References}

1. Hotta, M.; Nakata, R.; Katsukawa, M.; Hori, K.; Takahashi, S.; Inoue, H. Carvacrol, a component of thyme oil, activates PPAR $\alpha$ and $\gamma$ and suppresses COX-2 expression. J. Lipid Res. 2009, 51, 132-139. [CrossRef] [PubMed]

2. Hart, P.H.; Brand, C.; Carson, C.F.; Riley, T.V.; Prager, R.H.; Finlay-Jones, J.J. Terpinen-4-ol, the main component of the essential oil of Melaleuca alternifolia (tea tree oil), suppresses inflammatory mediator production by activated human monocytes. Inflamm. Res. 2000, 49, 619-626. [CrossRef] [PubMed]

3. Nogueira, M.N.M.; Aquino, S.G.; Rossa Junior, C.; Spolidorio, D.M.P. Terpinen-4-ol and alpha-terpineol (tea tree oil components) inhibit the production of IL-1 $\beta$, IL-6 and IL-10 on human macrophages. Inflamm. Res. 2014, 63, 769-778. [CrossRef] [PubMed]

4. Marshall, J.S.; Warrington, R.; Watson, W.; Kim, H.L. An introduction to immunology and immunopathology. Allergy Asthma Clin. Immunol. 2018, 14, 49. [CrossRef]

5. Burt, S. Essential oils: Their antibacterial properties and potential applications in foods-A review. Int. J. Food Microbiol. 2004, 94, 223-253. [CrossRef]

6. Zhang, L.; Yang, Z.; Huang, Z.; Zhao, M.; Li, P.; Zhou, W.; Zhang, K.; Zheng, X.; Lin, L.; Tang, J.; et al. Variation in Essential Oil and Bioactive Compounds of Curcuma kwangsiensis Collected from Natural Habitats. Chem. Biodivers. 2017, 14. [CrossRef]

7. Dhifi, W.; Bellili, S.; Jazi, S.; Bahloul, N.; Mnif, W. Essential Oils' Chemical Characterization and Investigation of Some Biological Activities: A Critical Review. Medicines 2016, 3, 25. [CrossRef] 
8. Fujimura, Y.; Kawano, C.; Maeda-Murayama, A.; Nakamura, A.; Koike-Miki, A.; Yukihira, D.; Hayakawa, E.; Ishii, T.; Tachibana, H.; Wariishi, H.; et al. A Chemometrics-driven Strategy for the Bioactivity Evaluation of Complex Multicomponent Systems and the Effective Selection of Bioactivity-predictive Chemical Combinations. Sci. Rep. 2017, 7, 2257. [CrossRef]

9. Hammoda, H.M.; Harraz, F.M.; Farag, M.A.; El-Aswad, A.F.; El-Hawiet, A.; Eid, A.M. Volatiles profiling and bioactivities of Cupressus spp. leaf and cone essential oils as analyzed via chemometrics tools. J. Essent. Oil Res. 2019, 31, 53-62. [CrossRef]

10. Sonnenberg, G.F.; Hepworth, M.R. Functional interactions between innate lymphoid cells and adaptive immunity. Nat. Rev. Immunol. 2019, 19, 599-613. [CrossRef]

11. Redgrove, K.A.; McLaughlin, E.A. The Role of the Immune Response in Chlamydia trachomatis Infection of the Male Genital Tract: A Double-Edged Sword. Front. Immunol. 2014, 5, 534. [CrossRef] [PubMed]

12. Ashley, N.T.; Weil, Z.M.; Nelson, R.J. Inflammation: Mechanisms, Costs, and Natural Variation. Annu. Rev. Ecol. Evol. Syst. 2012, 43, 385-406. [CrossRef]

13. Netea, M.G.; Balkwill, F.; Chonchol, M.; Cominelli, F.; Donath, M.Y.; Giamarellos-Bourboulis, E.J.; Golenbock, D.; Gresnigt, M.S.; Heneka, M.T.; Hoffman, H.M.; et al. A guiding map for inflammation. Nat. Immunol. 2017, 18, 826-831. [CrossRef] [PubMed]

14. Gea-Banacloche, J.C. Immunomodulation. In Principles of Molecular Medicine; Runge, M.S., Patterson, C., Eds.; Humana Press: Totowa, NJ, USA, 2006; pp. 893-904.

15. Huang, C.-F.; Lin, S.-S.; Liao, P.-H.; Young, S.-C.; Yang, C.-C. The Immunopharmaceutical Effects and Mechanisms of Herb Medicine. Cell. Mol. Immunol. 2008, 5, 23-31. [CrossRef]

16. Dong, L.; Liu, J.; Zhong, Z.; Wang, S.; Wang, H.; Huo, Y.; Wei, Z.; Yu, L. Dietary tea tree oil supplementation improves the intestinal mucosal immunity of weanling piglets. Anim. Feed Sci. Technol. 2019, 255, 114209. [CrossRef]

17. Kang, S.; Min, H. Ginseng, the 'Immunity Boost': The Effects of Panax ginseng on Immune System. J. Ginseng Res. 2012, 36, 354-368. [CrossRef]

18. Sandner, G.; Mueller, A.S.; Zhou, X.; Stadlbauer, V.; Schwarzinger, B.; Schwarzinger, C.; Wenzel, U.; Maenner, K.; van der Klis, J.D.; Hirtenlehner, S.; et al. Ginseng Extract Ameliorates the Negative Physiological Effects of Heat Stress by Supporting Heat Shock Response and Improving Intestinal Barrier Integrity: Evidence from Studies with Heat-Stressed Caco-2 Cells, C. elegans and Growing Broilers. Molecules 2020, 25, 835. [CrossRef]

19. Reyes, A.W.B.; Hop, H.T.; Arayan, L.T.; Huy, T.X.N.; Park, S.J.; Kim, K.D.; Min, W.; Lee, H.J.; Rhee, M.H.; Kwak, Y.-S.; et al. The host immune enhancing agent Korean red ginseng oil successfully attenuates Brucella abortus infection in a murine model. J. Ethnopharmacol. 2017, 198, 5-14. [CrossRef]

20. Salehi, B.; Sharifi-Rad, J.; Quispe, C.; Llaique, H.; Villalobos, M.; Smeriglio, A.; Trombetta, D.; Ezzat, S.M.; Salem, M.A.; Zayed, A.; et al. Insights into Eucalyptus genus chemical constituents, biological activities and health-promoting effects. Trends Food Sci. Technol. 2019, 91, 609-624. [CrossRef]

21. Barbosa, L.C.; Filomeno, C.A.; Teixeira, R.R. Chemical Variability and Biological Activities of Eucalyptus spp. Essential Oils. Molecules 2016, 21, 1671. [CrossRef]

22. Yin, C.; Liu, B.; Wang, P.; Li, X.; Li, Y.; Zheng, X.; Tai, Y.; Wang, C.; Liu, B. Eucalyptol alleviates inflammation and pain responses in a mouse model of gout arthritis. Br. J. Pharmacol. 2020, 177, 2042-2057. [CrossRef] [PubMed]

23. Joshi, A.; Sharma, A.; Bachheti, R.K.; Pandey, D.P. A Comparative Study of the Chemical Composition of the Essential oil from Eucalyptus globulus Growing in Dehradun (India) and Around the World. Orient. J. Chem. 2016, 32, 331-340. [CrossRef]

24. Sitaraman, R.; Rao, G. A Pediatric Case of Accidental Eucalyptus Oil Poisoning from New Delhi, India: Emergency Measures, Historical Context, and Implications for Practice. Cureus 2019, 11, e5734. [CrossRef]

25. Ittyachen, A.M.; George, G.R.; Radhakrishnan, M.; Joy, Y. Eucalyptus oil poisoning: Two case reports. J. Med. Case Rep. 2019, 13, 326. [CrossRef] [PubMed]

26. Flaman, Z.; Pellechia-Clarke, S.; Bailey, B.; McGuigan, M. Unintentional exposure of young children to camphor and eucalyptus oils. Paediatr. Child Health 2001, 6, 80-83. [CrossRef] [PubMed]

27. Sebei, K.; Sakouhi, F.; Herchi, W.; Khouja, M.L.; Boukhchina, S. Chemical composition and antibacterial activities of seven Eucalyptus species essential oils leaves. Biol. Res. 2015, 48, 7. [CrossRef] [PubMed] 
28. Nurdjannah, N.; Bermawie, N. Cloves. In Handbook of Herbs and Spices; Elsevier: Amsterdam, The Netherlands, 2012; pp. 197-215.

29. Jirovetz, L.; Buchbauer, G.; Stoilova, I.; Stoyanova, A.; Krastanov, A.; Schmidt, E. Chemical composition and antioxidant properties of clove leaf essential oil. J. Agric. Food Chem. 2006, 54, 6303-6307. [CrossRef]

30. Carson, C.F.; Hammer, K.A.; Riley, T.V. Melaleuca alternifolia (Tea Tree) oil: A review of antimicrobial and other medicinal properties. Clin. Microbiol. Rev. 2006, 19, 50-62. [CrossRef]

31. De Groot, A.C.; Schmidt, E. Tea tree oil: Contact allergy and chemical composition. Contact Derm. 2016, 75, 129-143. [CrossRef]

32. Białoń, M.; Krzyśko-Łupicka, T.; Nowakowska-Bogdan, E.; Wieczorek, P.P. Chemical Composition of Two Different Lavender Essential Oils and Their Effect on Facial Skin Microbiota. Molecules 2019, 24, 3270. [CrossRef]

33. Kıvrak, Ş. Essential oil composition and antioxidant activities of eight cultivars of Lavender and Lavandin from western Anatolia. Ind. Crops Prod. 2018, 117, 88-96. [CrossRef]

34. Serafino, A.; Sinibaldi Vallebona, P.; Andreola, F.; Zonfrillo, M.; Mercuri, L.; Federici, M.; Rasi, G.; Garaci, E.; Pierimarchi, P. Stimulatory effect of Eucalyptus essential oil on innate cell-mediated immune response. BMC Immunol. 2008, 9, 17. [CrossRef] [PubMed]

35. Jordan, A.R.; Racine, R.R.; Hennig, M.J.P.; Lokeshwar, V.B. The Role of CD44 in Disease Pathophysiology and Targeted Treatment. Front. Immunol. 2015, 6, 182. [CrossRef] [PubMed]

36. Yadav, N.; Chandra, H. Suppression of inflammatory and infection responses in lung macrophages by eucalyptus oil and its constituent 1,8-cineole: Role of pattern recognition receptors TREM-1 and NLRP3, the MAP kinase regulator MKP-1, and NFKB. PLoS ONE 2017, 12, e0188232. [CrossRef] [PubMed]

37. Juergens, U.R.; Engelen, T.; Racké, K.; Stöber, M.; Gillissen, A.; Vetter, H. Inhibitory activity of 1,8-cineol (eucalyptol) on cytokine production in cultured human lymphocytes and monocytes. Pulm. Pharmacol. Ther. 2004, 17, 281-287. [CrossRef]

38. Broz, P.; Dixit, V.M. Inflammasomes: Mechanism of assembly, regulation and signalling. Nat. Rev. Immunol. 2016, 16, 407-420. [CrossRef]

39. Ding, S.; Xu, S.; Ma, Y.; Liu, G.; Jang, H.; Fang, J. Modulatory Mechanisms of the NLRP3 Inflammasomes in Diabetes. Biomolecules 2019, 9, 850. [CrossRef]

40. Liu, L.; Dong, Y.; Ye, M.; Jin, S.; Yang, J.; Joosse, M.E.; Sun, Y.; Zhang, J.; Lazarev, M.; Brant, S.R.; et al. The Pathogenic Role of NLRP3 Inflammasome Activation in Inflammatory Bowel Diseases of Both Mice and Humans. J. Crohns. Colitis 2017, 11, 737-750. [CrossRef]

41. Paramel Varghese, G.; Folkersen, L.; Strawbridge, R.J.; Halvorsen, B.; Yndestad, A.; Ranheim, T.; Krohg-Sørensen, K.; Skjelland, M.; Espevik, T.; Aukrust, P.; et al. NLRP3 Inflammasome Expression and Activation in Human Atherosclerosis. J. Am. Heart Assoc. 2016, 5, e003031. [CrossRef]

42. Roe, K.; Gibot, S.; Verma, S. Triggering receptor expressed on myeloid cells-1 (TREM-1): A new player in antiviral immunity? Front. Microbiol. 2014, 5, 627. [CrossRef]

43. Goldstein, D.M.; Kuglstatter, A.; Lou, Y.; Soth, M.J. Selective p38 $\alpha$ Inhibitors Clinically Evaluated for the Treatment of Chronic Inflammatory Disorders. J. Med. Chem. 2010, 53, 2345-2353. [CrossRef] [PubMed]

44. Zhou, J.-y.; Tang, F.-d.; Mao, G.-g.; Bian, R.-l. Effect of alpha-pinene on nuclear translocation of NF-kappa B in THP-1 cells. Acta Pharmacol. Sin. 2004, 25, 480-484. [PubMed]

45. Zhou, J.-y.; Wang, X.-F.; Tang, F.-d.; Zhou, J.-Y.; Lu, G.-H.; Wang, Y.; Bian, R.-l. Inhibitory effect of 1,8-cineol (eucalyptol) on Egr-1 expression in lipopolysaccharide-stimulated THP-1 cells. Acta Pharmacol. Sin. 2007, 28, 908-912. [CrossRef]

46. Rouzer, C.A.; Marnett, L.J. Cyclooxygenases: Structural and functional insights. J. Lipid Res. 2009, 50, $29-34$. [CrossRef] [PubMed]

47. Batiha, G.E.; Alkazmi, L.M.; Wasef, L.G.; Beshbishy, A.M.; Nadwa, E.H.; Rashwan, E.K. Syzygium aromaticum L. (Myrtaceae): Traditional Uses, Bioactive Chemical Constituents, Pharmacological and Toxicological Activities. Biomolecules 2020, 10, 202. [CrossRef]

48. Mateen, S.; Rehman, M.T.; Shahzad, S.; Naeem, S.S.; Faizy, A.F.; Khan, A.Q.; Khan, M.S.; Husain, F.M.; Moin, S. Anti-oxidant and anti-inflammatory effects of cinnamaldehyde and eugenol on mononuclear cells of rheumatoid arthritis patients. Eur. J. Pharmacol. 2019, 852, 14-24. [CrossRef] [PubMed]

49. Pavesi, C.; Banks, L.; Hudaib, T. Antifungal and antibacterial activities of eugenol and non-polar extract of Syzygium aromaticum L. J. Pharm. Sci. Res. 2018, 10, 337-339. 
50. Ghofran, O.; Safari, T.; Shahraki, M.R. Effects of Eugenol on Pain Response to the Formalin Test and Plasma Antioxidant Activity in High Fructose Drinking Water in Male Rats. Int. J. Prev. Med. 2019, 10, 151.

51. Gaylor, R.; Michel, J.; Thierry, D.; Panja, R.; Fanja, F.; Pascal, D. Bud, leaf and stem essential oil composition of Syzygium aromaticum from Madagascar, Indonesia and Zanzibar. Int. J. Basic Appl. Sci. 2014, 3, 224-233. [CrossRef]

52. Prashar, A.; Locke, I.C.; Evans, C.S. Cytotoxicity of clove (Syzygium aromaticum) oil and its major components to human skin cells. Cell Prolif. 2006, 39, 241-248. [CrossRef]

53. Janes, S.E.; Price, C.S.; Thomas, D. Essential oil poisoning: N-acetylcysteine for eugenol-induced hepatic failure and analysis of a national database. Eur. J. Pediatr. 2005, 164, 520-522. [CrossRef] [PubMed]

54. Carrasco, F.R.; Schmidt, G.; Romero, A.L.; Sartoretto, J.L.; Caparroz-Assef, S.M.; Bersani-Amado, C.A.; Cuman, R.K.N. Immunomodulatory activity of Zingiber officinale Roscoe, Salvia officinalis L. and Syzygium aromaticum L. essential oils: Evidence for humor- and cell-mediated responses. J. Pharm. Pharmacol. 2009, 61, 961-967. [CrossRef] [PubMed]

55. Halder, S.; Mehta, A.K.; Mediratta, P.K.; Sharma, K.K. Essential oil of clove (Eugenia caryophyllata) augments the humoral immune response but decreases cell mediated immunity. Phytother. Res. 2011, 25, 1254-1256. [CrossRef] [PubMed]

56. Islamuddin, M.; Chouhan, G.; Want, M.Y.; Ozbak, H.A.; Hemeg, H.A.; Afrin, F. Immunotherapeutic Potential of Eugenol Emulsion in Experimental Visceral Leishmaniasis. PLoS Negl. Trop. Dis. 2016, 10, e0005011. [CrossRef]

57. Parker, D. CD80/CD86 signaling contributes to the proinflammatory response of Staphylococcus aureus in the airway. Cytokine 2018, 107, 130-136. [CrossRef]

58. Dibazar, S.P.; Fateh, S.; Daneshmandi, S. Immunomodulatory effects of clove (Syzygium aromaticum) constituents on macrophages: In vitro evaluations of aqueous and ethanolic components. J. Immunotoxicol. 2015, 12, 124-131. [CrossRef]

59. Choi, C.Y.; Park, K.-R.; Lee, J.-H.; Jeon, Y.J.; Liu, K.-H.; Oh, S.; Kim, D.-E.; Yea, S.S. Isoeugenol suppression of inducible nitric oxide synthase expression is mediated by down-regulation of NF-kappaB, ERK1/2, and p38 kinase. Eur. J. Pharmacol. 2007, 576, 151-159. [CrossRef]

60. Magalhães, C.B.; Casquilho, N.V.; Machado, M.N.; Riva, D.R.; Travassos, L.H.; Leal-Cardoso, J.H.; Fortunato, R.S.; Faffe, D.S.; Zin, W.A. The anti-inflammatory and anti-oxidative actions of eugenol improve lipopolysaccharide-induced lung injury. Respir. Physiol. Neurobiol. 2019, 259, 30-36. [CrossRef]

61. Persoons, J.H.; Schornagel, K.; Tilders, F.F.; De Vente, J.; Berkenbosch, F.; Kraal, G. Alveolar macrophages autoregulate IL-1 and IL-6 production by endogenous nitric oxide. Am. J. Respir. Cell Mol. Biol. 1996, 14, 272-278. [CrossRef]

62. Bachiega, T.F.; de Sousa, J.P.; Bastos, J.K.; Sforcin, J.M. Clove and eugenol in noncytotoxic concentrations exert immunomodulatory/anti-inflammatory action on cytokine production by murine macrophages. J. Pharm. Pharmacol. 2012, 64, 610-616. [CrossRef]

63. Sharifi-Rad, J.; Salehi, B.; Varoni, E.M.; Sharopov, F.; Yousaf, Z.; Ayatollahi, S.A.; Kobarfard, F.; Sharifi-Rad, M.; Afdjei, M.H.; Sharifi-Rad, M.; et al. Plants of the Melaleuca Genus as Antimicrobial Agents: From Farm to Pharmacy. Phytother. Res. 2017, 31, 1475-1494. [CrossRef] [PubMed]

64. Hammer, K.A.; Carson, C.F.; Riley, T.V.; Nielsen, J.B. A review of the toxicity of Melaleuca alternifolia (tea tree) oil. Food Chem. Toxicol. 2006, 44, 616-625. [CrossRef]

65. Low, P.; Clark, A.M.; Chou, T.-C.; Chang, T.-C.; Reynolds, M.; Ralph, S.J. Immunomodulatory activity of Melaleuca alternifolia concentrate (MAC): Inhibition of LPS-induced NF- $\mathrm{kB}$ activation and cytokine production in myeloid cell lines. Int. Immunopharmacol. 2015, 26, 257-264. [CrossRef] [PubMed]

66. Taniguchi, K.; Karin, M. NF-кB, inflammation, immunity and cancer: Coming of age. Nat. Rev. Immunol. 2018, 18, 309-324. [CrossRef] [PubMed]

67. Lee, S.-Y.; Chen, P.-Y.; Lin, J.-C.; Kirkby, N.S.; Ou, C.-H.; Chang, T.-C. Melaleuca alternifolia Induces Heme Oxygenase-1 Expression in Murine RAW264.7 Cells through Activation of the Nrf2-ARE Pathway. Am. J. Chin. Med. 2017, 45, 1631-1648. [CrossRef] [PubMed]

68. Budhiraja, S.S.; Cullum, M.E.; Sioutis, S.S.; Evangelista, L.; Habanova, S.T. Biological activity of Melaleuca alternifola (Tea Tree) oil component, terpinen-4-ol, in human myelocytic cell line HL-60. J. Manip. Physiol. Ther. 1999, 22, 447-453. [CrossRef] 
69. Salehi, B.; Mnayer, D.; Özçelik, B.; Altin, G.; Kasapoğlu, K.N.; Daskaya-Dikmen, C.; Sharifi-Rad, M.; Selamoglu, Z.; Acharya, K.; Sen, S.; et al. Plants of the Genus Lavandula: From Farm to Pharmacy. Nat. Prod. Commun. 2018, 13, 1385-1402. [CrossRef]

70. Wińska, K.; Mączka, W.; Łyczko, J.; Grabarczyk, M.; Czubaszek, A.; Szumny, A. Essential Oils as Antimicrobial Agents-Myth or Real Alternative? Molecules 2019, 24, 2130. [CrossRef]

71. Prashar, A.; Locke, I.C.; Evans, C.S. Cytotoxicity of lavender oil and its major components to human skin cells. Cell Prolif. 2004, 37, 221-229. [CrossRef]

72. Di Sotto, A.; Mazzanti, G.; Carbone, F.; Hrelia, P.; Maffei, F. Genotoxicity of lavender oil, linalyl acetate, and linalool on human lymphocytes in vitro. Environ. Mol. Mutagen. 2011, 52, 69-71. [CrossRef]

73. Giovannini, D.; Gismondi, A.; Basso, A.; Canuti, L.; Braglia, R.; Canini, A.; Mariani, F.; Cappelli, G. Lavandula angustifolia Mill. Essential Oil Exerts Antibacterial and Anti-Inflammatory Effect in Macrophage Mediated Immune Response to Staphylococcus aureus. Immunol. Investig. 2016, 45, 11-28. [CrossRef]

74. Chen, P.J.; Chou, C.C.; Yang, L.; Tsai, Y.L.; Chang, Y.C.; Liaw, J.J. Effects of Aromatherapy Massage on Pregnant Women's Stress and Immune Function: A Longitudinal, Prospective, Randomized Controlled Trial. J. Altern. Complement. Med. 2017, 23, 778-786. [CrossRef] [PubMed]

75. Kuriyama, H.; Watanabe, S.; Nakaya, T.; Shigemori, I.; Kita, M.; Yoshida, N.; Masaki, D.; Tadai, T.; Ozasa, K.; Fukui, K.; et al. Immunological and Psychological Benefits of Aromatherapy Massage. Evid. Based Complement. Alternat. Med. 2005, 2, 179-184. [CrossRef] [PubMed]

76. Sasannejad, P.; Saeedi, M.; Shoeibi, A.; Gorji, A.; Abbasi, M.; Foroughipour, M. Lavender essential oil in the treatment of migraine headache: A placebo-controlled clinical trial. Eur. Neurol. 2012, 67, 288-291. [CrossRef] [PubMed]

77. Ueno-Iio, T.; Shibakura, M.; Yokota, K.; Aoe, M.; Hyoda, T.; Shinohata, R.; Kanehiro, A.; Tanimoto, M.; Kataoka, M. Lavender essential oil inhalation suppresses allergic airway inflammation and mucous cell hyperplasia in a murine model of asthma. Life Sci. 2014, 108, 109-115. [CrossRef]

78. Lambrecht, B.N.; Hammad, H.; Fahy, J.V. The Cytokines of Asthma. Immunity 2019, 50, 975-991. [CrossRef]

79. Wang, W.; Shao, S.; Wang, S. The role for human nasal epithelial nuclear factor kappa B activation in histamine-induced mucin 5 subtype B overproduction. Int. Forum Allergy Rhinol. 2016, 6, 264-270. [CrossRef]

80. Lee, K.Y. M1 and M2 polarization of macrophages: A mini-review. Med. Biol. Sci. Eng. 2019, 2, 1-5. [CrossRef]

81. Horky, P.; Skalickova, S.; Smerkova, K.; Skladanka, J. Essential Oils as a Feed Additives: Pharmacokinetics and Potential Toxicity in Monogastric Animals. Animals 2019, 9, 352. [CrossRef]

82. Tammar, S.; Salem, N.; Bettaieb Rebey, I.; Sriti, J.; Hammami, M.; Khammassi, S.; Marzouk, B.; Ksouri, R.; Msaada, K. Regional effect on essential oil composition and antimicrobial activity of Thymus capitatus L. J. Essent. Oil Res. 2019, 31, 129-137. [CrossRef]

83. Peterfalvi, A.; Miko, E.; Nagy, T.; Reger, B.; Simon, D.; Miseta, A.; Czéh, B.; Szereday, L. Much More Than a Pleasant Scent: A Review on Essential Oils Supporting the Immune System. Molecules 2019, 24, 4530. [CrossRef] [PubMed]

84. Bakkali, F.; Averbeck, S.; Averbeck, D.; Idaomar, M. Biological effects of essential oils-A review. Food Chem. Toxicol. 2008, 46, 446-475. [CrossRef] [PubMed]

85. Mehdizadeh, L.; Moghaddam, M. Essential Oils: Biological Activity and Therapeutic Potential. In Therapeutic, Probiotic, and Unconventional Foods; Elsevier: Amsterdam, The Netherlands, 2018; pp. 167-179.

(C) 2020 by the authors. Licensee MDPI, Basel, Switzerland. This article is an open access article distributed under the terms and conditions of the Creative Commons Attribution (CC BY) license (http://creativecommons.org/licenses/by/4.0/). 